\title{
Iron Deficiency Anaemia and Childhood Carries: A Case Report
}

Faiza Nouh", Salima Elfagi, Mariam Omar, Ashmisa Eltuhami

Department of Nutrition, Faculty of Public Health, University of Benghazi

DOI: $10.36347 /$ sjds.2020.v07i04.003

| Received: 06.04.2020 | Accepted: 14.04.2020 | Published: 17.04.2020

*Corresponding author: Faiza Nouh

\section{Abstract}

Severe early childhood caries (SECC) is a public health problem among children. Malnutrition is a condition commonly prevalent in children with SECC. This case report investigated the iron deficiency among child with SECC. The nutritional status of the child was assessed based on anthropometric measurements and clinical tests. By applying the criteria established by the World Health Organization. Our results show that SECC is strongly associated with anaemia, indicating that clinicians and dentists should provide treatment to improve both the oral hygiene and the nutritional status of children with SECC.

Keywords: Iron, Anaemia, Carries.

Copyright @ 2020: This is an open-access article distributed under the terms of the Creative Commons Attribution license which permits unrestricted use, distribution, and reproduction in any medium for non-commercial use (NonCommercial, or CC-BY-NC) provided the original author and source are credited.

\section{INTRODUCTION}

Early childhood caries (ECC) is the development of one or more decayed, tooth missing due to caries, or tooth surfaces filling in any primary tooth in a child under the age of six years. Sever early childhood caries consequences include low life quality due to pain, chewing difficulty, and range to impairment of health, including iron deficiency, anaemia (IDA)[1]. Consequently, (IDA) lead to retardation in children growth and development. According to the World Health Organization (WHO), anaemia is a public health phenomenon that affects more than one billion people worldwide. (IDA)'s prevalence is greatest among preschool children. The main cause of (IDA) is low iron intake and absorption by feeding. (IDA) is an indicator of malnutrition, and it may lead to defect in psychomotor system development during childhood [2]. Recent published papers showed an association between caries and nutritional status more precisely between ECC and iron deficiency in the body. This report presents the clinical case of a girl (4 years old) who presented with severe childhood caries associated with sever iron deficiency anaemia[3-6].

\section{CASE REPORT}

The patient attended Benghazi Paediatric Hospital on (April, 2019), where she was reported to be in severe pain and having difficulty eating. According to her clinical history, the patient was the middle of three children who lived on a farm south of Benghazi [7-11]. The patient came to the hospital with her mother and father. Within the clinical history, her mother reported that the child had never been brushed her teeth or went to a dentist. Her dietary intake was accomplished by the frequent consumption of fluids that contain high sweetened milk, sugar and sweetened soft foods. The mother mentioned that the child is using feeding bottles both day and night. During clinical examination, extensive caries lesions with crown destruction and dental fistula in all teeth were observed. A panoramic radiographic examination revealed periodontal abscesses in all teeth.

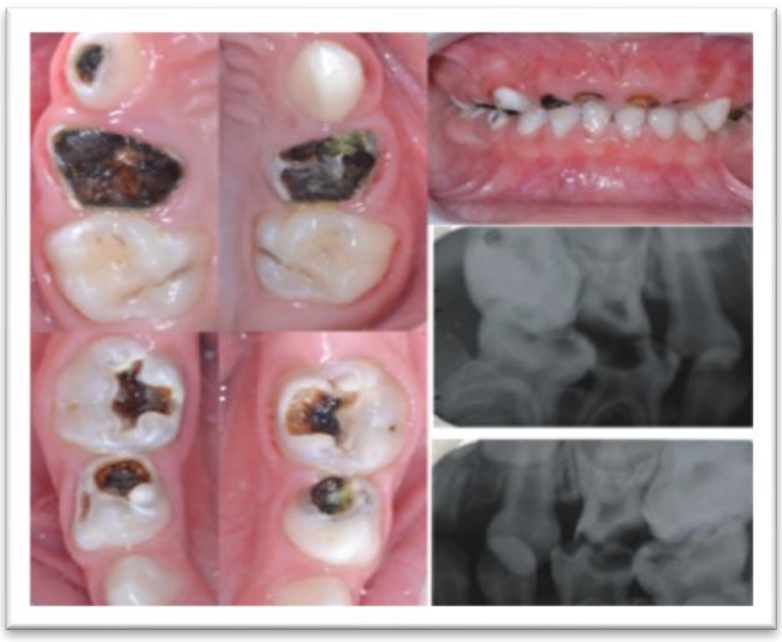

Fig-1: Teeth caries lesions

The physical examination showed the patient weighed $10.60 \mathrm{~kg}$ and measured $94.5 \mathrm{~cm}$ in height. 
These measurements put the child on the 10th percentile of the growth chart established by the world health organisation whish used as growth watch tool in Libya. The deficient in growth is most likely due to the lack of proper nutrition that is necessary for this age group.

The laboratory tests showed that the child had a low hematocrit (23.8\%; normal value: $40 \%$ - 52\%), low levels of haemoglobin $(8 \mathrm{~g} / \mathrm{dL}$; normal value: 14.0 $18.0 \mathrm{~g} / \mathrm{dL})$, serum ferretin $(12 \mathrm{ng} / \mathrm{mL}$; normal value: 28 - $365 \mathrm{ng} / \mathrm{mL}$ ), serum vitamin D $17.6 \mathrm{mg} / \mathrm{dl}$ (normal value more than $30 \mathrm{mg} / \mathrm{dl}$ ). Moreover, according to the neurological evaluations the child showed delayed neurological and cognitive development. According to this complete assessment, the child was diagnosed with sever early childhood carries and iron deficiency anaemia

A multidisciplinary intervention plan was developed to treat the oral infection and anaemia. Firstly, she initially received a 5-day oral hygiene regimen (chlorhex iodine three times a day and oral administration antibiotics (amoxicillin $125 \mathrm{mg}$ per $\mathrm{kg}$ /day). Secondly, to treat her severe anaemia, she received a blood transfusion $(250 \mathrm{~mL}$ red blood cells filtered and irradiated). The transfusion was administered due to the immediate need for extraction of teeth fragments and to avoid any further loss of the child's growth and development. On the third day of blood transfusion, and according to the joint planning of the medical and dental teams, 4 extractions (maxillary left quadrant) were performed under conscious sedation. On the $8^{\text {th }}$ day of treatment journey, ferrous sulphate $(5 \mathrm{mg} / \mathrm{kg} / \mathrm{d})$ is administrated orally until normal blood parameters were reached and stabilized. Both, haemoglobin and hematocrit level had improved $(10.5 \mathrm{~g} / \mathrm{dl}$ and $34.3 \% \mathrm{~g} / \mathrm{dL}$, respectively). Accordingly, eight more extractions were performed (maxillary and mandibular right quadrants) under intravenous sedation. The last tooth extractions (mandibular left quadrant) were per formed on the 18th day of treatment journey, under intravenous sedation. On the 25 th day, she presented improvements in clinical and laboratory aspects (hematocrit, 35.2\%; haemoglobin, $12.10 \mathrm{~g} / \mathrm{dL}$; ferretin, $43.5 \mathrm{ng} / \mathrm{dL}$; and serum iron, $31 \mu \mathrm{g} / \mathrm{dL}$ ). The family members were referred to departments of Nutrition, Neurology, and Paediatric Dentistry. Further dental treatment was planned, including the manufacture of full maxillary and mandibular dentures and the monitoring of permanent teeth eruption with the goal of preventing caries and promoting good general health. At nutrition Department, the child was provided with nutrient dense diet according to her current weight and height. The child was prescribed 1200 calories per day. These calories were divided daily into 5 servings of starch, 4 servings of meats ((iron sources)), 2 servings of vegetables, 3 servings of fruits, 2 servings of milk, and 3 servings of fats. These servings were transferred and written into detailed nutrients dense varied diet every day by the dietitian. After two weeks the child became $12 \mathrm{~kg}$ and in one month she became $14.6 \mathrm{~kg}$. Continuous nutritional follow up will be held for six months.

\section{DISCUSSION}

Anemia can be caused by several factors, including dietary factors, genetic (congenital) factors, environmental factors, and inflammatory processes. Children with SECC may have higher rates of anemia and iron deficiency for various reasons. Children with SECC may consume cow's milk excessively, which reduces the absorption of iron. In addition, children with SECC have untreated caries that often cause pain or discomfort, and they may thus have difficulty in chewing certain iron- and vitamin $\mathrm{C}$-rich foods, such as red meat and citrus fruits, respectively. Furthermore, children with SECC may suffer from acute or chronic inflammation, resulting from pulpitis and periapical abscess and fistula, and such inflammatory complications may induce the production of cytokines that suppresses the synthesis of Hgb. Wang et al. [12] showed a significant association between anemia and a monotonous diet. Clarke et al.[13] found that most children with S-ECC presented evidence of inadequate iron intake and presented a low level of serum ferritin $(80 \%)$, iron reduction $(24 \%)$, iron deficiency $(6 \%)$, and anemia (11\%). Tang et al. [14] studied 101 children between 2 and 5 years of age with S-ECC and revealed that $9 \%$ and $46 \%$ had anemia and iron deficiency, respectively. The average rate of ferritin was $29.6 \pm$ $17.9+\mathrm{g} / \mathrm{L}$ while hemoglobin was $115.1 \pm 10.1 \mathrm{~g} / \mathrm{L}$. A case-control study with 266 children (mean age 3.4 years) also revealed greater iron deficiencies in children with S-ECC. The authors concluded that children with S-ECC were twice as likely to have low levels of ferritin and more than 6 times as likely to have anemia by iron deficiency as children with no caries. According to physical examinations performed by a pediatrician and a neurologist, the patient presented delayed neuropsychomotor system involvement. The WHO states that the highest prevalence of anemia is in preschool children (47\%), and that disease can affect a child's neurological development. A medical literature review concluded that there is current evidence that iron deficiency early in life is associated with impaired neurological development and that iron supplementation of anemic school-aged children reduces the anemia and may improve neuropsychological outcomes.

\section{CONCLUSION}

SECC may be a contributing factor for iron deficiency, anemia, and impaired weight gain in young children. SECC may represent a risk factor for anemia in children. Further studies are needed to examine lifestyle and socioeconomic risk factors that may be associated with the malnourished status of these children. Preventive strategies should be developed to reduce the risk of anemia, iron deficiency, and impaired weight gain in children with SECC. 


\section{REFERENCES}

1. Grant CC, Wall CR, Brewster D, Nicholson R, Whitehall J, Super L, Pitcher L. Policy statement on iron deficiency in pre- school- aged children. Journal of paediatrics and child health. 2007 Jul;43(7- 8):513-21.

2. Oliveira MA, Osório MM. Consumo de leite de vaca e anemia ferropriva na infância. Jornal de Pediatria. 2005 Oct;81(5):361-7.

3. Mohebbi SZ, Virtanen JI, Vahid- Golpayegani M, Vehkalahti MM. Feeding habits as determinants of early childhood caries in a population where prolonged breastfeeding is the norm. Community dentistry and oral epidemiology. 2008 Aug;36(4):363-9.

4. American Academy of Pediatrics. Policy on early childhood caries (ECC): classifications, consequences, and preventive strategies. Pediatric dentistry. 2008;30(7 Suppl):40.

5. Milnes AR. Description and epidemiology of nursing caries. Journal of public health dentistry. 1996 Jan;56(1):38-50.

6. Salima Elfagi, Ashmisa Eltuhami, Faiza Nouh, Salmeen Andelnaser, Howida Jomaa, Asma Agila, Jamila Mansour. Study of relationship between maternal knowledge about complementary feeding and the nutritional status of preschool children at Benghazi. Internatioanl Journal of Multidisciplinary Studies; 6(2):1232-1239.

7. Tsai AI, Chen CY, Li LA, Hsiang CL, Hsu KH. Risk indicators for early childhood caries in Taiwan. Community dentistry and oral epidemiology. 2006 Dec;34(6):437-45.
8. Shaw NS, Yeh WT, Pan WH. Prevalence of iron deficiency in the general population in Taiwan. 中 華民國營養學會雜誌. 1999 Feb 1;24(1):119-38.

9. Petrova D, Stoykov M, Angelova S. Oral Health and General Somatic Status in ChildhoodOverview. In Varna Medical Forum 2018 (Vol. 7, pp. 265-271).

10. Manios Y, Moschonis G, Kolotourou M, Keskin Y, Sur H, Kocaoglu B, Hayran O. Iron deficiency prevalence and dietary patterns by school district in Istanbul. Journal of human nutrition and dietetics. 2007 Dec;20(6):549-57.

11. Nouh F, Omar M, Elmabsout A, Younis M. Demand Feeding versus Scheduled Feeding during early life: Influence of feeding practice on obesity at early childhood: a systematic review of published evidence. Scholars Journal of Applied Medical Sciences. 2017; 5(5C):1959-1969.

12. Clarke M, Locker D, Berall G, Pencharz P, Kenny DJ, Judd P. Malnourishment in a population of young children with severe early childhood caries. Pediatric dentistry. 2006 May 1;28(3):254-9.

13. Omar M, Nouh F, Younis M, Nabil N, Mohamed $\mathrm{N}$, Mohamed $\mathrm{H}$. Intrauterine Growth and Adult Diseases from Theory to Practices. Asian Journal of Pregnancy and Childbirth. 2018:1-3.

14. Thomas CW, Primosch RE. Changes in incremental weight and well-being of children with rampant caries following complete dental rehabilitation. Pediatric dentistry. 2002;24(2):10913. 